\title{
ESTUDO DE TEMPOS E MOVIMENTOS NO PROCESSO PRODUTIVO DE UMA ORGANIZAÇÃO DO RAMO ALIMENTÍCIO
}

\author{
Lenuzia Santos do Nascimento (UFRN, Brasil) lenuzia_14@hotmail.com \\ Paula Flaviane Pinheiro do Nascimento (UFRN, Brasil) paulinha_f.f@hotmail.com \\ Karoline Isabelle de Almeida Pereira (UFRN, Brasil) karolineisabelle_@hotmail.com \\ Mariane Cristina Lima de Souza (UFRN, Brasil) marianecristina21@hotmail.com
}

Resumo: $O$ presente artigo tem como objetivo propor melhorias no ambiente organizacional em detrimento da análise do processo produtivo por meio do estudo de tempos e movimentos, expondo a importância do gerenciamento de processos em empresas do setor alimentício para aquisição de uma maior vantagem competitiva. A metodologia utilizada baseou-se em pesquisas bibliográfica, exploratória e descritiva. Foram utilizados: o mapeamento dos processos desenvolvidos no estabelecimento, para que fosse possível uma melhor visualização das atividades envolvidas, o procedimento operacional padrão, visando à excelência na prestação dos serviços, e o estudo de tempos e movimentos para identificar o tempo real por meio de cronometragem e assim os tempos normal e padrão. Foram medidas ainda as distâncias percorridas pelos funcionários e os métodos por eles utilizados para a execução das atividades. Por meio destes dados, foram propostas melhorias que resultaram em reduções de elementos que não agregam valor ao serviço oferecido, como distâncias desnecessárias percorridas e fadiga do operador. Constatou-se que essas reduções podem levar ao aumento da produtividade e possibilita tornar ótimo o processo produtivo do serviço de almoço self-service de uma lanchonete do município de Natal/RN.

Palavras-chave: Estudo de tempos e movimento. Gerenciamento de processos. Análise de processos.

\section{Introdução}

Conforme dados disponibilizados pela 2011. No âmbito interno do país, só o Associação Brasileira de Indústria de Alimentos (2012), o setor de alimentos possui significante representatividade na economia do país, sendo responsável por 426,7 bilhões de reais, o que foi equivalente a 9,3\% do PIB em segmento de food service, ou seja, o mercado de alimentação fora do lar movimentou, em 2012, a importância de 100,5 bilhões de reais. No contexto instaurado sobre a economia do ramo alimentício, para sobreviverem, as 
empresas devem adaptar seus sistemas produtivos, visando a sua melhoria contínua. Os prazos de entrega, a qualidade e a diminuição dos custos são os principais pontos de aprimoramento ininterrupto. Tendo em vista estes preceitos, o estudo de tempos e movimentos foi aplicado para a análise do processo produtivo do self-service de uma lanchonete localizada no município de Natal/RN, presente no mercado há 20 anos, a fim de propor melhorias no ambiente organizacional que propiciem o aumento da produtividade.

Segundo Barnes (1977), o estudo de tempos e movimentos visa desenvolver o sistema preferido, podendo ser o de menor custo, padronizá-lo, determinar o tempo utilizado pelo trabalhador que labuta em um ritmo normal, para executá-lo e orientar o treinamento do trabalhador de acordo com o método definido.

Desse modo, o artigo objetiva analisar o processo produtivo, por meio do estudo de tempos e movimentos, elaborando maneiras que favoreçam a eficiência no desempenho do trabalho e, consequentemente, obter produtividade. Por meio do estudo de tempos e movimentos, foi possível diagnosticar os problemas da produção e desenvolver o melhor método para minimizar ou mitigá-los. Para isso, é necessário perceber os aspectos das atividades diante da capacidade do trabalhador de modo a acelerar o processo produtivo.

A produtividade é intrínseca ao estudo dos tempos e movimentos, pois sendo as condições de trabalho condizentes com as limitações dos operários, a atividade é melhor executada, reduzindo a fadiga, bem como o período utilizado no processo e consequentemente o rendimento operacional se torna maior. Por meio dos dados obtidos, as devidas melhorias foram propostas, trazendo resultados satisfatórios para a empresa.

$\mathrm{O}$ artigo está estruturado da seguinte maneira: primeiramente são apresentados, de modo global, todos os assuntos. Posteriormente, são feitas definições do mapeamento de processo; seguindo de conceitos condizentes com o estudo de tempos e movimentos. No quarto tópico, expomos a metodologia aplicada neste estudo, aderindo, como o quinto item, uma análise mais detalhada sobre a empresa escolhida. Em sexto lugar, foram expostos os resultados e suas melhorias. Por fim, o artigo é concluído, apresentado em maior âmbito suas contribuições.

\section{Mapeamento de Processos}

Segundo Hunt (1996), a análise dos processos mapeados permite a redução de custos no desenvolvimento de produtos e serviços, a redução nas falhas de integração entre sistemas e melhoria do desempenho da organização, além de ser uma excelente ferramenta para possibilitar o melhor entendimento dos processos atuais e eliminar ou simplificar aqueles que necessitam de mudança.

O fluxograma de processo, segundo Campos (1992), é fundamental para a padronização e posterior entendimento do processo. Essa ferramenta facilita a visualização ou identificação dos produtos produzidos, dos 
clientes e fornecedores internos e externos do processo, das funções, das responsabilidades e dos pontos críticos.

O mapofluxograma, de acordo com Barnes (1977), representa a movimentação física de um item por meio dos centros de processamento disposto no arranjo físico de uma instalação produtiva, seguindo uma sequência ou rotina fixa. Identifica assim movimentos desnecessários ou que ocupem um longo espaço de tempo e ainda aperfeiçoa o arranjo físico visando mitigar desperdícios com deslocamentos. Para sua representação, faz-se o uso de simbologias cujos significados estão dispostos no Quadro 1, a seguir.

QUADRO 1: SIGNIFICADO DA
SIMBOLOGIA PARA MAPEAMENTO DE
\begin{tabular}{|c|l|}
\multicolumn{2}{c}{ PROCESSOS } \\
\hline \multicolumn{1}{|c|}{ LEGENDA } \\
\hline$\square$ & Operação (produz ou realiza) \\
$\Rightarrow$ & Inspeção (verifica) \\
$\square$ & Transporte (movimenta) \\
$\nabla$ & Espera (interfere) \\
$\square$ & Armazenamento (retém) \\
$\square$ & Combinação de operação e insperção \\
\hline
\end{tabular}

Fonte: Adaptado de Krick (1971)

\subsection{Procedimento Operacional Padrão}

O procedimento operacional padrão (POP) faz parte da gestão da qualidade, estando atrelada ao ciclo PDCA, presente em seus procedimentos para obter a manutenção dos resultados. Rocha (2012) retrata que "o POP é a descrição sistematizada e padronizada de uma atividade técnica-assistencial, com o intuito de garantir/atingir o resultado esperado por ocasião de sua realização, livre de variações indesejáveis".

Objetivando o melhoramento de processos e serviços, o procedimento operacional padrão é responsável por garantir o alcance do resultado desejado, minimizando os desvios na realização das atividades operacionais, descrevendo todos os passos dos processos, com o intuito de adquirir a qualidade (COLENGHI, 1997).

De acordo com Rocha (2012), o POP é uma ferramenta da gestão da qualidade que pretende alcançar a excelência na prestação do serviço, passando a diminuir os erros nas ações rotineiras, de modo dinâmico, passível de evolução buscando profundas transformações culturais, nos aspectos técnicos e políticoinstitucionais.

\section{Estudo de Tempos e Movimentos}

O estudo de tempos e movimentos foi introduzido por Taylor, para a racionalização dos métodos de trabalho do operário e fixação de tempos padrões para execução de cada atividade, passando elas a serem mais claras e detalhadas. Esse estudo, segundo Barnes (1977), pode ser definido como um estudo sistemático dos métodos de trabalhos, com objetivo de desenvolver o método preferido, padronizar o melhor método, determinar o tempo padrão e treinar os operadores.

É um estudo sistemático que tem como finalidade desenvolver o método de menor custo e padronizar esse sistema, determinando o tempo gasto por uma pessoa qualificada e devidamente treinada trabalhando em um ritmo 
normal, para executar uma tarefa ou operação específica.

Para Slack et al. (2009), o estudo de tempo e movimentos é dividido em etapas. Para o tempo, faz-se necessário observar, medir e avaliar o ritmo de trabalho, constituindo a etapa 1; em seguida, ajusta-se os tempos observados para normalizá-los de acordo com a fórmula: avaliação observada/avaliação padrão; encontrado o tempo normal, calcula-se a média dos tempos normais (ou básicos), formando a $3^{\circ}$ etapa, levando em consideração as tolerâncias para o tempo de descanso e necessidades físicas e psicológicas do trabalhador.

\section{Materiais e Métodos Aplicados}

A natureza do presente artigo é um estudo de caso, visto que o trabalho caracteriza-se como sendo um estudo em profundidade, baseado em uma análise intensiva empreendida em uma única organização (BRUYNE; HERMAN; SCHOUTHEETE, 1991). Os dados colhidos foram do tipo qualitativo e quantitativo.

A obtenção desses foi necessária, visando realizar a análise e proposições de possíveis melhorias no processo produtivo da empresa estudada. $\mathrm{O}$ procedimento adotado foi a visita in loco, com observações diretas e conversas informais com os funcionários, clientes e o proprietário do estabelecimento, além de aplicação de questionários semiestruturados com perguntas fechadas, junto à população de trabalhadores do estabelecimento para traçar seus perfis.
Os dados referentes aos tempos foram obtidos por meio de cronometragem das atividades do processo produtivo do almoço. Também foi permitida a medição da área e distâncias que os funcionários percorrem para realizar suas funções. Esta foi realizada com o uso de fita métrica.

Quanto aos procedimentos técnicos, foi realizada pesquisa bibliográfica, exploratória e descritiva. Foi utilizada, como base de dados, a consulta em artigos e livros relacionados ao tema exposto no trabalho. A pesquisa também foi norteada pela análise frente aos diagnósticos no setor alimentício do Brasil no ano de 2012, apresentando como foco o ramo de food service.

\section{Estudo de Caso: Lanchonete}

A lanchonete em estudo está no mercado há, aproximadamente, 20 anos. Inicialmente, o proprietário possuía apenas um carro de lanches, sendo pioneiro nesse setor em Natal/RN. Após 8 anos, esse pequeno negócio faliu por má administração. Alguns anos depois, com foco mais abrangente e um maior investimento, o proprietário abriu uma lanchonete em um estabelecimento na Av. Romualdo Galvão, Natal/RN.

Com o crescimento da demanda, o estabelecimento foi transferido para um local próximo do anterior, entretanto com um espaço ampliado. Atualmente o Nero's Lanches conta com três unidades de lanchonetes, com apenas uma aberta 24 horas por dia, sendo esta a unidade em foco. 
O estabelecimento oferece um mix de produtos amplo: sanduíches (simples, especial, Nero, entre outros), açaí, batata frita, bebidas não alcoólicas (refrigerantes, suco, milk-shake), sorvete e, mais recentemente, sopa (de frango, carne e feijão), além de oferecer refeição do modo self-service, no horário do almoço. Estas ofertas de produtos variados, aliadas às promoções e preços baixos são características que conquistam os clientes do estabelecimento que são, geralmente, jovens e trabalhadores locais de classe média.

Entretanto, o estabelecimento não possui um controle financeiro, contabiliza instintivamente o faturamento de, aproximadamente, $15 \mathrm{mil}$ sanduíches por mês, o que equivale a aproximadamente $60 \%$ do faturamento mensal. É composto de 12 funcionários que estão distribuídos em 3 turnos, estando um desses em treinamento inicial.

Dentre os trabalhadores, $83,3 \%$ são do sexo feminino e $39 \%$ possuem faixa etária entre 20 e 42 anos. Apenas a atendente possui ensino médio completo, representando $8,3 \%$ da população total dos trabalhadores. O restante dos funcionários possui escolaridade incompleta, sendo $31 \%$ destes com ensino fundamental incompleto.

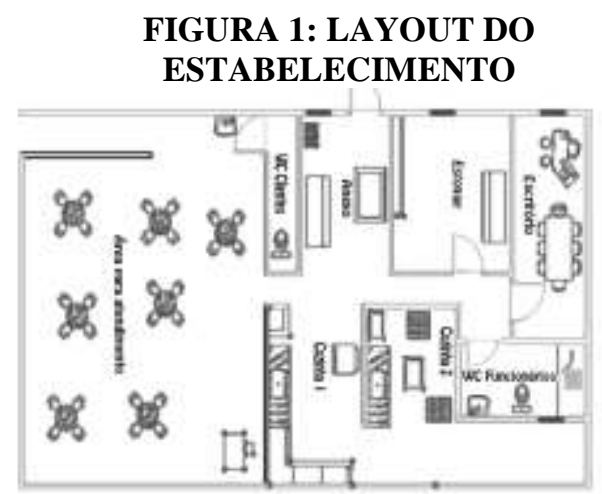

A empresa apresenta equipamentos sem muita tecnologia agregada. São eles: Três fogões (sendo um industrial, um de seis bocas e outro de apenas duas bocas); três freezers; uma geladeira; um refrigerador e uma chapa.

\subsection{Atividade Desenvolvida}

As atividades da lanchonete resumem-se a basicamente três: preparação de lanches, preparação de almoço e atendimento ao cliente.

Normalmente, os funcionários distribuem-se da seguinte maneira: duas pessoas revezam-se no atendimento e no caixa, e duas, na cozinha. Entretanto, quando o movimento está alto, essa alocação fica comprometida, podendo uma atendente auxiliar na cozinha, para reduzir gargalos na produção e acelerar a entrega dos pedidos.

O espaço físico da cozinha para disposição dos funcionários é adequado, entretanto, ao exceder esse número, nota-se cruzamento de pessoas no fluxo da produção. Essa situação leva ao desgaste físico, fadiga e estresse dos funcionários, que necessitam adequar-se à demanda, não assumindo, assim, uma função fixa. A estrutura organizacional da empresa foi elaborada pela equipe pesquisadora em conjunto com o proprietário do estabelecimento, como demonstrado na Figura 2. 
FIGURA 2: ORGANOGRAMA DA

LANCHONETE

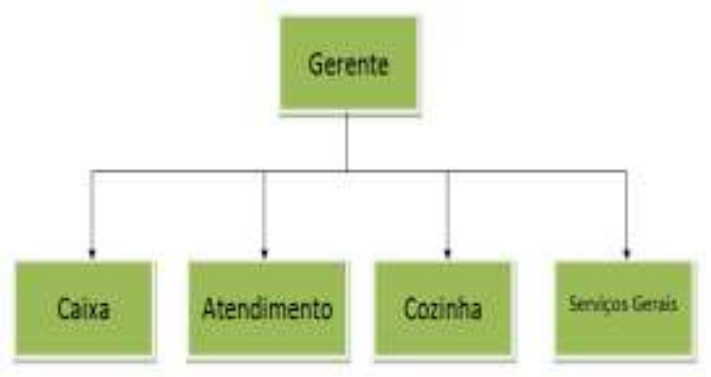

A Figura 2 representa o organograma da empresa estudada, o que mostra uma estrutura simples de uma empresa de pequeno porte. Há apenas o proprietário com poder de decisão considerado, também, gerente. Os outros setores do estabelecimento são: o caixa, o setor de atendimento ao cliente, a cozinha, onde são preparados os lanches e as refeições, e o setor de serviços gerais.

Em sua estrutura física, a empresa dispõe de uma área de atendimento, dois banheiros, sendo um para clientes e outro para funcionários (ambos unissex), duas cozinhas: cozinha 1 (frontal a área de atendimento), onde são preparados os lanches; cozinha 2 (interna), local onde são preparadas as refeições (almoço).

$\mathrm{O}$ ambiente conta ainda com um anexo (chamado de estoque 1) lateral a cozinha 1, onde são armazenadas as carnes, os frangos, entre outros condimentos; a dispensa (estoque 2), onde são alocadas bebidas, verduras, legumes, insumos para o lanche, etc.; e um escritório (estoque 3), onde ficam guardados os pertences dos funcionários e os fardos de feijão, arroz e macarrão utilizados para o almoço.

\subsection{Procedimento Operacional Padrão}

\section{da Lanchonete}

Diariamente, o almoço é um serviço oferecido na empresa Nero's. Os alimentos são armazenados em três pontos: no estoque, no escritório e no anexo próximo à cozinha 1 . No estoque, são armazenados os insumos para a produção dos lanches, as bebidas e alguns dos ingredientes para o almoço, como os legumes e verduras.

No escritório, os fardos de feijão, arroz e macarrão. No anexo, estoca-se as carnes e os frangos. O procedimento operacional padrão está esquematizado no fluxograma (Figura 3).

Inicialmente, os alimentos do escritório e estoque são transferidos para a cozinha 2 , onde são selecionados, lavados e cozidos. Concomitantemente, a carne e o frango são levados do anexo para a cozinha 1, onde são cortados em pedaços menores.

Esses são então transferidos para a cozinha 2, onde é realizada sua lavagem e adicionado ao tempero para cozinhar ou assar (dependendo do cardápio do dia).

$\mathrm{O}$ sequenciamento das atividades assim como as distâncias relacionadas a cada atividade está descrito nas Tabelas 1, 2 e 3. 
FIGURA 3: FLUXOGRAMA PADRÃO DOS PROCESSOS DE PREPARAÇÃO DE ALIMENTOS DA LANCHONETE

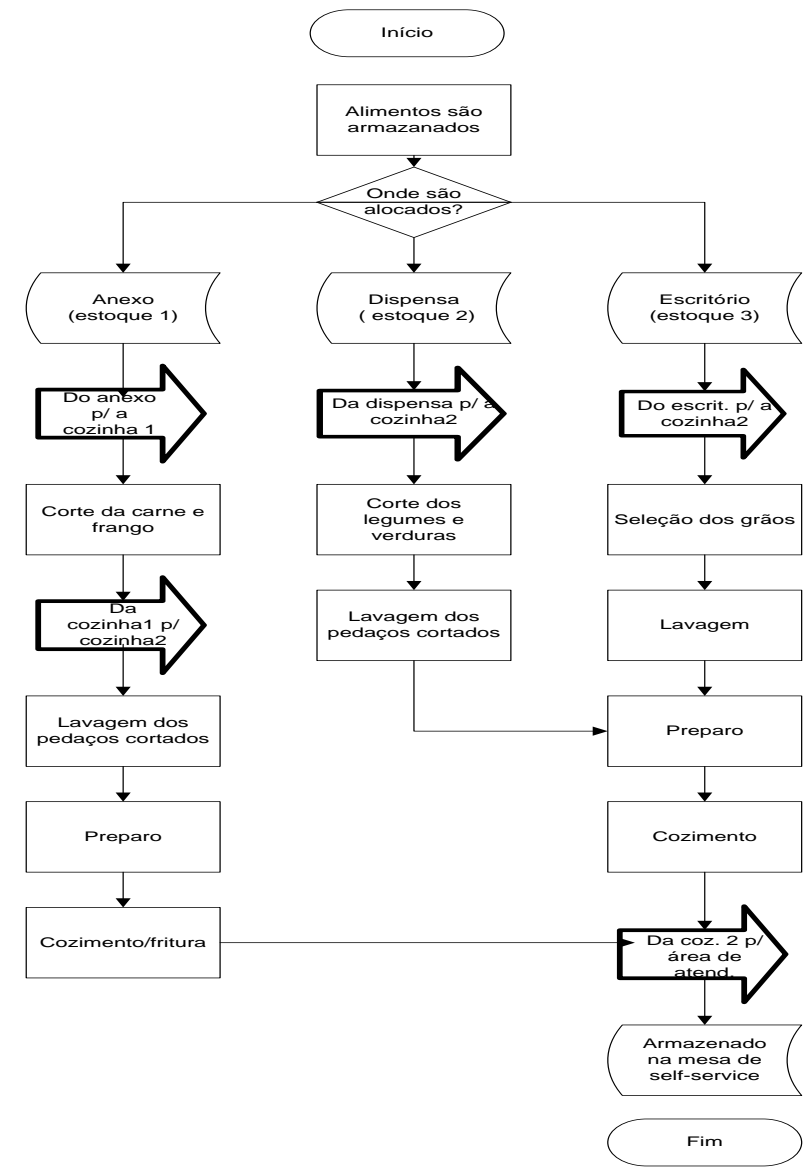

TABELA 1: PROCESSOS QUE PARTEM QUE PARTEM DO ESTOQUE 1

\begin{tabular}{|c|c|c|}
\hline Simbolo & Descriçäo & Distincia \\
\hline & Ingredientes no estoque 1 & \\
\hline & Do estoque 1 para cozinha 1 & $4,2 \mathrm{~m}$ \\
\hline$\square$ & Corte da carne e do frango & \\
\hline & Da cozinha 1 para cozinha 2 & $2,8 \mathrm{~m}$ \\
\hline & Lavagem da came e lavagem do frango & \\
\hline & Preparo tempero & \\
\hline & $\begin{array}{c}\text { Cozimento ou fritura da carne e do } \\
\text { frango }\end{array}$ & \\
\hline & Da cozinha 2 para area de atendimento & $7,7 \mathrm{~m}$ \\
\hline & Armazenado na mesa de self-service & \\
\hline
\end{tabular}

O total das distâncias percorridas para os processos que partem do estoque 1, 2 e 3 são respectivamente, 14,7 metros, 13,8 metros e
15,3 metros. Estas distâncias são fatores que não agregam valor ao serviço oferecido. Por isso, vale destacar isso a importância de analisá-las de tal modo que se possam reduzir estes espaços, aumentando a dinâmica do processo.

\section{TABELA 2: PROCESSOS QUE PARTEM QUE} PARTEM DO ESTOQUE 2

\begin{tabular}{|c|c|c|}
\hline Simbolo & Descriçào & Distancia \\
\hline & Ingredientes no estoque 2 & - \\
\hline & Do estoque 2 para cozinha 2 & $6,1 \mathrm{~m}$ \\
\hline & Corte dos legumes e verduras & - \\
\hline & Lavagem dos legumes e verduras & - \\
\hline & Preparo:tempero & - \\
\hline & Cozimento dos legumes e verduras & - \\
\hline & $\begin{array}{l}\text { Da cozinha } 2 \text { para irea de } \\
\text { atendimento }\end{array}$ & $7,7 \mathrm{~m}$ \\
\hline & Armazenado na mesa de self-service & - \\
\hline
\end{tabular}

TABELA 3: PROCESSOS QUE PARTEM QUE PARTEM DO ESTOQUE 3

\begin{tabular}{|c|c|c|}
\hline Simbolo & Descriçào & Distância \\
\hline & Ingredientes no estoque 3 & - \\
\hline & Do estoque 3 para cozinha 2 & $7,6 \mathrm{~m}$ \\
\hline & Seleção dos grãos & - \\
\hline & Lavagem dos grãos & - \\
\hline & Preparo tempero & - \\
\hline & Cozimento & - \\
\hline & $\begin{array}{c}\text { Da cozinha } 2 \text { para área de } \\
\text { atendimento }\end{array}$ & $7,7 \mathrm{~m}$ \\
\hline & Armazenado na mesa de self-service & - \\
\hline
\end{tabular}

\subsection{Análise dos tempos}

Como visualizado no fluxograma, há a realização de operações que necessitam de 
elevado tempo de preparação no processo produtivo dos alimentos gerados no selfservice. Efetuamos, portanto a cronometragem das operações déficit do processo, para determinar o tempo padrão de algumas atividades executadas pelos funcionários. Foram elaboradas, primeiramente, seis cronometragens, conforme apresentado na Tabela 4

TABELA 4: TEMPOS CRONOMETRADOS

\begin{tabular}{|c|c|c|c|c|c|c|}
\hline \multicolumn{7}{|c|}{ Corte da carne } \\
\hline Cronometragem & 1 & 2 & 3 & 4 & 5 & 6 \\
\hline Tempo cronometrado (min) & 57,32 & 57,15 & 59,08 & 58,1 & 56,55 & 58,5 \\
\hline \multicolumn{7}{|c|}{ Corte do frango } \\
\hline Cronometragem & 1 & 2 & 3 & 4 & 5 & 6 \\
\hline Tempo cronometrado (min) & 22,51 & 24,05 & 23,17 & 22,38 & 23,2 & 23,58 \\
\hline \multicolumn{7}{|c|}{ Corte da verdura } \\
\hline Cronometragem & 1 & 2 & 3 & 4 & 5 & 6 \\
\hline Tempo cronometrado (min) & 32,56 & 33,04 & 31,12 & 32,11 & 33,19 & 32,48 \\
\hline
\end{tabular}

Fonte: Elaboração dos autores

Utilizados o número de ciclos para determinar a quantidade de amostra necessária, adotamos como nível de confiança $95 \%$ o que equivale a 1,96, por serem utilizados seis amostras determinamos o valor do coeficiente d_2=2,534 de acordo com a Tabela 5 .

\section{TABELA 5: COEFICIENTE PARA CALCULAR O NÚMERO DE CRONOMETRAGENS}

\begin{tabular}{c|ccccc}
\hline $\mathbf{N}$ & $\mathbf{2}$ & $\mathbf{3}$ & $\mathbf{4}$ & $\mathbf{5}$ & $\mathbf{6}$ \\
\hline $\mathrm{d}_{2}$ & 1,128 & 1,693 & 2,059 & 2,326 & 2,534 \\
\hline
\end{tabular}

Para encontrar o desvio padrão da amostra de medidas (s), necessitamos do valor da amplitude da amostra (R) e o coeficiente em função do número de cronometragem $\left(d_{2}\right)$ que poderá ser representado como (Equação 1).

$$
s=\frac{R}{d_{2}}
$$

Assim, podemos identificar qual o valor do desvio padrão no corte da carne que corresponde a $s=0,998$, no corte do frango $\mathrm{s}=0,660$ e no corte da verdura $\mathrm{s}=0,817$ consideremos também a precisão de +- $10 \%$. Criando a Tabela 6.

TABELA 6: MÉDIA E DESVIO PADRÃO DA AMOSTRA

\begin{tabular}{l|ccc}
\hline \multicolumn{1}{c|}{ Operação } & $\begin{array}{c}\text { Média } \\
(\mathrm{x})\end{array}$ & $\begin{array}{c}\text { Desvio } \\
(\mathrm{s})\end{array}$ & $\begin{array}{c}\text { Coeficiente de } \\
\text { variação }\end{array}$ \\
\hline $\begin{array}{l}\text { Corte da } \\
\text { carne }\end{array}$ & 57,78 & 0,998 & 0,017 \\
$\begin{array}{l}\text { Corte do } \\
\text { frango }\end{array}$ & 23,15 & 0,660 & 0,029 \\
$\begin{array}{l}\text { Corte da } \\
\text { verdura }\end{array}$ & 32,41 & 0,817 & 0,025 \\
\hline
\end{tabular}

Fonte: Elaboração dos autores

Adquirimos como maior coeficiente de variação o tempo que corresponde ao corte do frango com um $(\mathrm{s} / \mathrm{x})$ de valor 0,029 podemos então adotá-lo como base para o cálculo de medidas necessárias, conforme o número de ciclo. Dessa forma, utilizamos a Equação 21para o estudo de tempos por cronômetro:

$$
N=\left(\frac{100 Z s}{a x}\right)^{2}
$$


Onde:

$\mathrm{N}=\mathrm{N}^{\mathrm{o}}$ de medidas

$\mathrm{z}=\mathrm{n}^{\mathrm{o}}$ de desvios padrão, correspondente ao

grau de confiança $\mathrm{C}$ desejado

$\mathrm{s}=$ desvio padrão da amostra de medidas

$\mathrm{a}=$ precisão desejada em $\%$

$\mathrm{x}=$ média da amostra de medidas

Substituindo os valores acima, segundo o corte do frango, podemos adquirir um resultado de $\mathrm{N}=0,323$ significando a não necessidade de realizar mais medições de amostra. Podemos então prosseguir com a busca do tempo padrão, primeiramente com aquisição de dados percentuais referentes à eficiência do operador, como também a tolerância dos mesmos.

Nas operações selecionadas, o corte da carne e do frango relaciona-se a uma atividade efetuada por apenas uma funcionária (A), e o corte da verdura é realizado por outra operária (B). De acordo com esses dados, podemos analisar a atividade e atribuir valores baseados no contexto da velocidade normal corresponder a 100\%, acelerado a mais de $100 \%$, e lento menor que $100 \%$ surgindo, dessa maneira, a eficiência inerente à verificação da observação direta.

TABELA 7: EFICIÊNCIA E FATOR DE TOLERÂNCIA

\begin{tabular}{c|ccc}
\hline Operária & $\begin{array}{c}\text { Eficiência } \\
(\mathbf{E F})\end{array}$ & $\begin{array}{c}\text { Tolerância } \\
(\mathbf{T})\end{array}$ & $\begin{array}{c}\text { Fato de } \\
\text { tolerância } \\
(\text { FT) }\end{array}$ \\
\hline A & $100 \%$ & $18 \%$ & $118 \%$ \\
B & $98 \%$ & $16 \%$ & $116 \%$ \\
\hline
\end{tabular}

Fonte: Elaboração dos autores

As tolerâncias constantes foram atribuídas da seguinte maneira: para os funcionários A e B, adotou-se o critério de que as tolerâncias em condições pessoais consistem substancialmente a $5 \%$, pois tempo para atender as necessidades pessoais diárias são, em média, 20 minutos enquanto que as tolerâncias relativas à fadiga de ambas operárias são de $4 \%$. No que condiz com às tolerâncias variáreis, como o estado em que é realizado o trabalho que geralmente é em pé, de forma curvada, adotamos mais uma porcentagem de $2 \%$ para a trabalhadora $\mathrm{B}$, pois ela ainda tem a oportunidade de operar em algum momento sentada, enquanto a funcionária A trabalha apenas em pé numa mesma posição de elevado período, obtendo uma porcentagem de 3\%. Também é exigida uma força muscular na atividade feita pela operária $\mathrm{A}$, atribuindo-lhe mais um valor de $1 \%$. No que se refere às condições ambientais, consideramos uma porcentagem de $5 \%$ devido à temperatura, à monotonia e aos ruídos advindos do posto de trabalho. A partir desses dados, podemos realizar o cálculo de tempo Normal (TN) e tempo padrão (TP), por meio das Equações 3 e 4.

$$
T N=T R \frac{E F}{100}
$$

$$
T P=T N \frac{F T}{100}
$$

Para determinar o tempo padrão, identificamos a média do tempo real de cada operação que se encontra na Tabela 3, e substituímos na equação III, para obter o tempo normal. Logo após, utilizamos o valor do tempo normal na Equação 4, para encontrar o tempo padrão. 


\section{ReLAlnEP}

TABELA 8: DETERMINANDO O TEMPO

PADRÃO

\begin{tabular}{l|lll}
\hline Operária & Operação & $\begin{array}{l}\text { Tempo } \\
\text { Normal } \\
\text { (TN) }\end{array}$ & $\begin{array}{l}\text { Tempo } \\
\text { padrão } \\
\text { (TP) }\end{array}$ \\
\hline A & $\begin{array}{l}\text { Corte da } \\
\text { carne }\end{array}$ & 57,78 & 68,18 \\
A & $\begin{array}{l}\text { Corte do } \\
\text { frango } \\
\text { Corte da } \\
\text { verdura }\end{array}$ & 23,15 & 27,32 \\
B & 31,76 & 36,84 \\
\hline
\end{tabular}

Fonte: Elaboração dos autores

Desse modo, podemos adquirir o tempo padrão de cada operação, de maneira que possam ser efetuadas posteriores melhorias quanto ao método de trabalho executado pelos funcionários. Nesse contexto, a padronização dos procedimentos é fundamental, visto que minimiza tempo, por exigir um determinado período na operação de cada atividade. Desta feita, a parte da empresa é qualificar os operários.

\section{Resultados}

De acordo com o estudo de tempos e movimentos, pode ser observado que os funcionários andam em uma distância relativamente grande em relação à simplicidade da tarefa.

Analisando o layout da empresa, nota-se a estrutura inadequada do local. Foi verificado que, na cozinha 2, havia uma abertura que foi vedada com o intuito de atenuar o fluxo de pessoas na cozinha. Todavia, essa aparente solução não foi satisfatória.

A distância percorrida entre os estoques 2 e 3 aumentou, e o fluxo de pessoas ficou mais complexo, por ter apenas uma passagem para a cozinha 2. Sugere-se um re-layout que possibilite a redução dessa área percorrida pelos trabalhadores na transferência dos insumos do estoque para a cozinha 2.

Além disso, a quantidade de estoques no estabelecimento é desnecessária. Os inputs armazenados no escritório (estoque 3) poderiam ser melhor distribuídos na despensa (estoque 2), visto que esta possui potencial estrutural para isso.

Uma organização no local pode alocar mais produtos e eliminar o estoque 3, deixando-o apenas como escritório para guardar os pertences dos funcionários e acomodar possíveis reuniões. Com tais alterações, o fluxo de pessoas, informações e materiais tornar-seia mais limpo, ou seja, com menos cruzamentos, como pode ser observado ao comparar os mapafluxogramas antes da reorganização (Figura 4, 5 e 6).

Diante da modificação do mapafluxograma, os processos caminham de forma mais rápida e dinâmica. Após a eliminação do escritório como estoque, as distâncias percorridas pelos funcionários para transferir os insumos da despensa (estoque 2), para a cozinha $2 \mathrm{e}$, em seguida, o produto final para a área de atendimento que antes era percorrido um total de 15,3 metros, foi reduzido para 7,6 metros. Ou seja, foram eliminados 7,7 metros de percurso desnecessários no processo. 
FIGURA 4 E 5: MAPAFLUXOGRAMA DA PREPARAÇÃO DE REFEIÇÕES E LANCHES ANTES DA REORGANIZAÇÃO
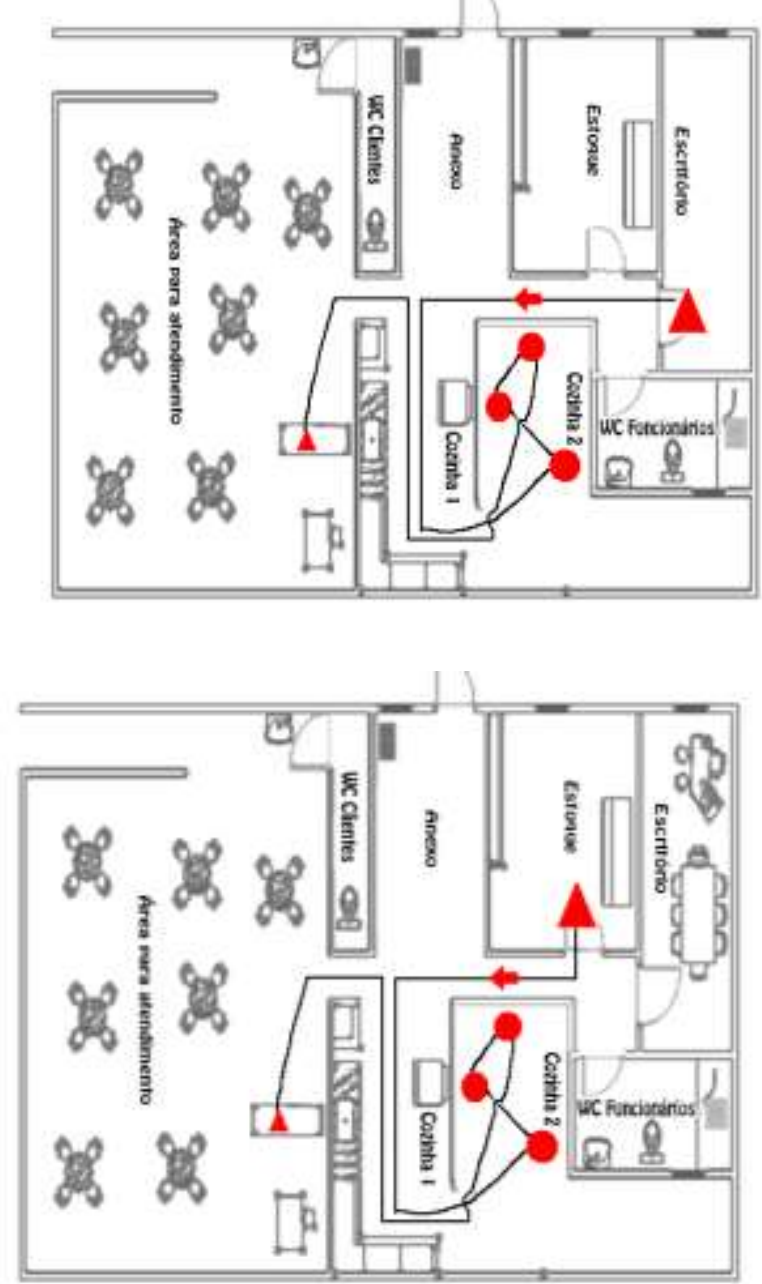

Outro ponto de melhoria é o método utilizado para o corte da carne e frango. É uma atividade que requer esforço físico, realizada em pé por uma funcionária. Esta chega a ficar mais de $2 \mathrm{~h}$ na mesma posição, realizando essa função. Foi observada a fadiga da funcionária $\mathrm{e}$, consequentemente, a demora em terminar a função, visto que, por estar cansada, ela acaba realizando maiores pausas. Este papel poderia ser atribuído para um funcionário do sexo masculino, visto que naturalmente possui maior resistência. Outra solução seria trocar de funcionário entre o corte da carne e frango. Seria possível ainda que estabelecimento disponibilizasse uma pausa entre essas duas atividades consecutivas, aliviando a fadiga e, consequentemente, agilizando o processo.

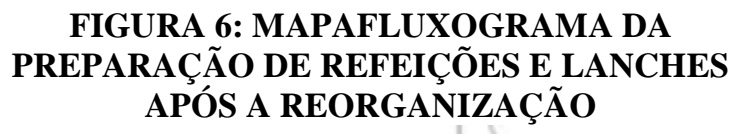

FIGURA 6: MAPAFLUXOGRAMA DA PREPARAÇÃO DE REFEIÇÕES E LANCHES APÓS A REORGANIZAÇÃO

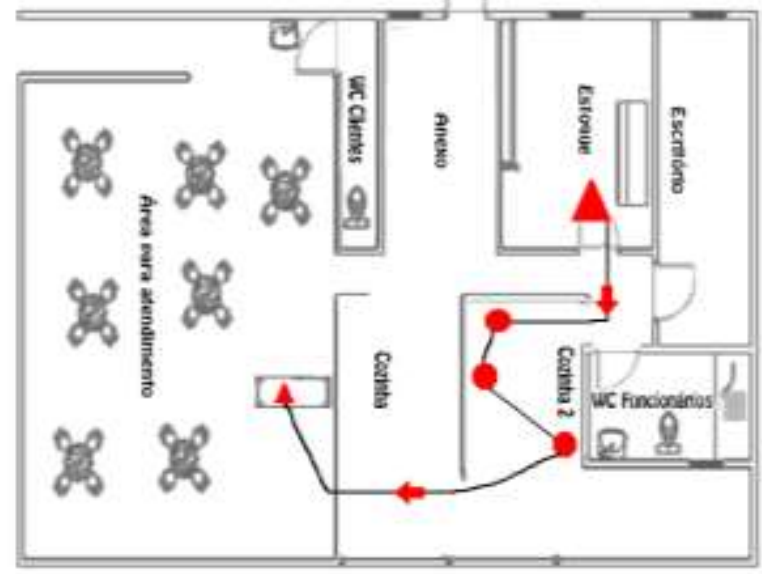

$\mathrm{Na}$ atividade do corte das verduras, a funcionária poderia realizar na posição sentada, diminuindo seu desconforto e cansaço. Com isso, a trabalhadora demoraria um tempo maior para apresentar desgaste físico e reduzir seu ritmo de trabalho.

A parede que divide a cozinha 1 da área de atendimento não é completa, oferecendo uma espécie de balcão entre eles. Assim/Desse modo, alguns alimentos são transferidos por intermédio dela para outro funcionário que está organizando o self-service. Se tal prática viesse a ser padrão, haveria também a redução da distância, assim como simplificaria o fluxo de pessoas, reduzindo cruzamentos.

\section{Considerações Finais}

O estudo de tempos e movimentos possui fundamental importância na melhoria da produtividade de qualquer organização, uma vez que a partir dele é possível encontrar erros 
e padronizar o melhor método para a produção.

A análise do tempo de cada atividade crucial do processo foi fundamental para o estudo, bem como a observação do layout vigente.

Desse modo, tivemos como propósito nesse artigo o gerenciamento dos processos produtivos e estudos relativos aos tempos e movimentos efetuados em uma organização de ramo alimentício, o que resultou em dados fundamentais para a proposta de melhorias quanto ao tempo de produção e percurso realizado pelos funcionários. Foi utilizada como fonte de pesquisa a aquisição de tempos por meio de cronômetro e amostragem.

A partir da análise do layout da empresa pôdese identificar uma melhoria em seu espaço físico para um melhor fluxo de pessoas durante todo o processo produtivo por meio da otimização da armazenagem de produtos, agilizando o processo e minimizando os movimentos durante as atividades.

Por meio de tais estudos, foi possível obter o tempo padrão e também propor um re-layout da empresa para reduzir o fluxo e, consequentemente, melhorar os processos de tempos, pois se verificou que, em decorrência do elevado tempo de produção e movimentação durante o expediente de trabalho, ocasionava além de perdas produtivas, também desconforto, fadiga e cansaço, devido ao grande esforço físico requerido dos funcionários na empresa.

\section{Referências}

\section{ABIA - Associação Brasileira das Indústrias da Alimentação. Disponível em: <http://www.abia.org.br/vst/default.asp>. Acesso em: abr. de 2013.}

BARNES, Ralph Mosser. Estudo de movimentos e de tempos: projeto e medida do trabalho. 6 ed. São Paulo: Edgar Blücher, 1977.

BRUYNE, P.; HERMAN, J.; SCHOUTHEETE, M. Dinâmica da pesquisa em ciências sociais. Rio de Janeiro: Francisco Alves, 1991.

COLENGHI, Vitor Mature. O\&M e Qualidade Total: uma integração perfeita. Rio de Janeiro: Qualitymark. 1997.

CAMPOS, V.F. TQC: Controle da qualidade total (no estilo japonês). Belo Horizonte: Fundação Christiano Ottoni: Bloch Editores, 1992.

HUNT, V. D. Process Mapping: how to reengineer your business processes. John Wiley \& Sons, Canada. 1996.

KRICK, E.V. Métodos e Sistemas. v. 2. Rio de Janeiro: Livros Técnicos e Científicos, 1971.

MARTINS, Petrônio G.; LAUGENI, Fernando P. Administração da Produção. São Paulo: Saraiva, 1998.

ROCHA, F. C. V. Procedimento Operacional Padrão Enfermagem. HGV. Piauí, 2012. Disponível em <http://www.hgv.pi.gov.br/download/20120 7/HGV20_d747ba8b2b.pdf> Acesso em 20 abril 2013.

SLACK, Nigel et al. Administração da produção. 3 ed. São Paulo: Atlas, 2009. 